\title{
Rencana Pengembangan Lanskap Agrowisata Di Kawasan Bukit Piantus Sejangkung
}

\author{
SABAHAN ${ }^{*}$, ERIK DARMANSYAH² \\ 1Program Studi Manajemen Bisnis Pariwisata Politeknik Negeri Sambas \\ 2Pusat Penelitian dan Pengabdian Kepada Masyarakat Politeknik Negeri Sambas \\ *Email: sabahan_polteksbs@yahoo.com
}

\section{ABSTRACT \\ Landscape Development Plan Agrotourism in Piantus Hill Area, Sejangkung District}

This study aims to create an agrotourism development in the Piantus Hill area. This study is limited to the planning department for agrotourism. The planning process includes the preparation of studies, concepts, data collection, analysis, synthesis, and planning of agrotourism area. Data taken the form of primary and secondary data were analyzed descriptively and spatially. The concept of planning in this research is to develop a community-based agrotourism area. The concept was developed into the concept of landscape space, circulation, and activities. Space was developed following the existing site conditions, with the creation of supporting facilities for cultural tourism activities, without losing the natural atmosphere that existed at the site so that the expected tourism activities and community life runs beiringan. The space is classified into two, namely the cultural tourism and non-tourism and culture. Circulation network developed at the site should be classified into two, namely the circulation for tourism activities (primary and sekender) and society. Tourist activities that will be developed are appropriate activities with resources pertaining to the agricultural potential of the research sites. The results of this study in the form of agro-based regional planning community to empower the potential and the resources available in the Piantus village so as to improve the welfare of local communities and to improve the satisfaction of tourists in the tour. The planned space divided into three rooms ecotourism, agrotourism supporting room, and a non agrotourism. In each room there are certain functions such as receiving, services, aquaculture, post-harvest and other space in accordance with the existing space. Activities that can be done in this agro activity can be active and passive. The planned activities are supported with adequate facilities that include agro tourism facilities and service facilities. Moreover, the addition of utilities such as water, electricity, sewage treatment and waste, and communication and promotion will further strengthen the presence of agrotourism in the Piantus Hill area future.

Keywords: agrotourism, piantus hill, the development plan 


\section{Pendahuluan}

Perubahan konsep dan paradigma dalam pembangunan nasional dapat memicu perkembangan di segala bidang. Perbaikan konsep perencanaan, pengelolaan sumberdaya dan kelembagaan baik di tingkat pusat dan daerah sangatlah diperlukan. Lahirnya otonomi daerah diharapkan berperan dalam mengoptimalkan semua fungsi pengelolaan wilayah baik administrasi maupun pembangunannya, sehingga daerah dapat mengembangkan potensi yang dimilikinya berdasarkan kearifan lokal (local wisdom).

Banyak sumberdaya wisata potensial yang dimiliki Indonesia diantaranya adalah wisata berbasis pada sumberdaya alam termasuk lanskap pedesaan dan pertanian yang memiliki kekayaan dan keragaman yang tinggi dalam berbagai bentukan serta adat dan budaya lokal yang menyertainya. Basis pengembangan ini sangat vital mengingat sebagian besar wilayah Indonesia masih berupa pedesaan yang didominasi oleh akivitas pertanian dengan segala tradisi budayanya. Kondisi tersebutlah yang memiliki nilai atraktif dan turistik yang berpotensi untuk dikelola dan dikembangkan bagi kesejahteraan manusia.

Salah satu kawasan yang berpotensi untuk dikembangkan sektor pariwisatanya adalah kawasan bukit Piantus Sejangkung. Kawasan bukit Piantus ini berada di kecamatan Sejangkung yang meliputi dua desa yaitu desa Piantus dan desa Parit Raja kecamatan Sejangkung, Kabupaten Sambas ini merupakan salah satu bagian dari kawasan pertanian yang sangat berpotensi menjadi kawasan wisata yang populer. Dengan semakin berkembangnya wisata di kawasan ini, diharapkan kawasan ini dapat menjadi kawasan wisata yang dapat meningkatkan kesejahteraan masyarakat.

Penelitian ini didasarkan oleh suatu pemikiran akan perlunya perencanaan lanskap kawasan agrowisata yang melibatkan peran serta masyarakat di suatu daerah yang merupakan suatu bentuk pemanfaatan sumber daya alam dan manusia dalam usaha pelestarian lingkungan dan peningkatan kesejahteraan masyarakat setempat.

Kawasan bukit Piantus Sejangkung merupakan salah satu desa yang memiliki lanskap pertanian dan pedesaan yang menarik. Desa ini merupakan wilayah yang bertopografi relatif datar dengan pola permukiman umumnya mengarah ke jalan.

Karakter lain yang bisa ditemukan pada desa ini adalah karakter khas kehidupan masyarakat setempat. Masyarakat desa pada umumnya memiliki adat istiadat masyarakat melayu yang hingga kini masih mereka pegang teguh seperti penggunaan bahasa daerah, kesenian tradisional, pemukiman penduduk, dan juga tata krama dalam kehidupan seharihari. Selain itu, aktivitas ekonomi yang berbasis dari hasil bumi atau pertanian yang berlangsung di masyarakat juga selalu memperhatikan prinsip-prinsip kekeluargaan.

\section{Metode Penelitian}

\subsection{Waktu, Bahan, dan Alat yang Digunakan}

Penelitian yang meliputi tahapan persiapan hingga konsep dan perencanaan serta penyerahan laporan akhir dilakukan selama 6 (enam) bulan, terhitung dari bulan Mei 2016 sampai dengan Oktober 2016.

Bahan-bahan yang digunakan dalam penelitian ini adalah: 
1) Peta Rupa Bumi desa Piantus

2) Peta Administrasi desa Piantus

3) Peta Citra Landsat-ETM Kecamatan Sejangkung

4) RTRW/RPJP kabupaten Sambas

5) Data dari Badan Pusat Statistik, Kabupaten Sambas, Kecamatan Sejangkung, dan desa Piantus.

Sedangkan alat yang digunakan dalam program ini berupa perangkat keras (hardware) antara lain laptop, GPS, kamera, dan printer. Sedangkan perangkat lunak (Software) yang digunakan meliputi microsoft office (Word, Exel, Power Point) dan Arc View GIS 3.3. Perangkat keras dan lunak tersebut digunakan sebagai alat untuk pengetikan, tabulasi data, tracking lokasi, dokumentasi, percetakan, analisis data, pengolahan data vektor dan pembuatan peta, pencatatan dan pendeleniasian peta di lapangan.

\subsection{Prosedur Pelaksanaan Penelitian}

Prosedur pelaksanaan penelitian ini meliputi tiga tahapan yang meliputi:

1. Persiapan, tahapan ini merupakan tahapan yang dilakukan sebelum melaksanakan riset. Hal-hal yang dilakukan dalam tahapan ini berupa penentuan sasaran dan tujuan penelitian, serta penyiapan perangkat-perangkat penelitian.

2. Riset, tahapan ini mecakup kegiatan inventarisasi, analisis dan sintesis data. Tahapan ini dilakukan terhadap data yang diperoleh berdasarkan studi pustaka, wawancara, dan pengamatan secara langsung di lapangan. Selain itu juga dibuat peta tematik digital yang berdasarkan faktor-faktor dasar yang terdiri dari sumber daya agrowisata di lokasi penelitian.

3. Perencanaan kawasan, merupakan tahapan yang dilakukan untuk membuat konsep dan penentuan zona-zona potensial agrowisata berbasis masyarakat di kawasan bukit Piantus kecamatan Sejangkung kabupaten Sambas Kalimantan Barat.

Tahapan persiapan bertujuan untuk menentukan sasaran, tujuan, dan penyiapan perangkat-perangkat penelitian. Tahapan riset mencakup tahapan inventarisasi, analisis dan sintesis data. Inventarsasi merupakan kegiatan pengumpulan dan penyediaan data/informasi yang dibutuhkan sesuai dengan ruang lingkup penelitian. Keseluruhan data, baik data primer maupun sekunder dikumpulkan untuk diedit dan ditabulasi sebelum dilakukan pengolahan dan analisis data. Data primer yang bersifat kualitatif dianalisis secara deskriptif dan tabulatif sesuai dengan tujuan penelitian.

Penelitian ini secara umum menggunakan metode deskriptif kualitatif. Metode deskriptif terdiri dari metode identifikasi yang merupakan kegiatan yang dilakukan setelah semua informasi dan data terkumpul yang didasarkan atas fokus penelitian yang telah disebutkan di atas. Identifikasi sederhana dilakukan berdasarkan poin-poin penting dan hal-hal yang menarik maupun kesamaan informasi maupun pandangan responden melalui wawancara dan kuisioner. Metode inventarisasi, yaitu pengelompokan data berdasarkan hasil identifikasi yang disandingkan dalam satu kesatuan data yang didasarkan fokus studi serta sumber informasi. Inventarisasi juga dilakukan sebagai dasar penyusunan kerangka kerja penelitian. 
Interpretasi/penafsiran dilakukan setelah pengaitan antar data, interpretasi juga dilakukan dengan disertai teori yang relevan. Sesuai dengan kaidah penelitian kualitatif, melalui metode analisis yang dipilih, peneliti dapat membuat interpretasi dan dapat mempunyai kekuatan argumentasi didasarkan data yang diperoleh di lapangan.

Zonasi adalah pendekatan yang dapat membantu menjaga nilai konservasi dan keberlanjutan suatu kawasan wisata. Penentuan zona kawasan agrowisata dilakukan berdasarkan kriteria tertentu sesuai dengan potensi yang dimiliki masing-masing zona kawasan tersebut.

Sedangkan tahapan perencanaan kawasan agrowisata merupakan tahap terakhir dari penelitian ini. Proses ini merupakan perealisasian hasil sintesis baik berupa block plan kawasan dan juga sintesis berupa deskripsi yang lebih rinci untuk kemudian dilakukan pengembangan dan penataan kawasan agrowisata dengan menggunakan konsep ecovillage. Selain hasil analisis dan sintesis yang nantinya mempengaruhi produk perencanaan, kemampuan berkreasi, imajinasi dan inovasi dari perencana juga menjadi faktor penting dalam merumuskan perencanaan tersebut baik dalam bentuk master plan.

\subsection{Analisis}

Analisis data meliputi analisis deskriptif dan analisis spasial. Metode analisis data potensi agrowisata yang digunakan dalam penelitian ini didukung oleh analisis potensi objek/atraksi, analisis kesesuaian, analisis daya dukung kawasan, pemetaan partispatif. Analisis potensi objek/atraksi mencakup analisis terhadap aspek keberadaan, estetika dan keaslian, transportasi dan aksessibilitas, atraksi dan keunikan, fasilitas pendukung, ketersediaan air bersih dan dukungan masyarakat.

Pengembangan agrowisata di suatu kawasan dimulai dengan menentukan objek dan atraksi agrowisata yang tersedia dan selanjutnya dinilai potensinya. Dalam penelitian ini, penilaian potensi kawasan agrowisata dilakukan dengan menggunakan metode modifikasi Mc Kinnon (1986) dan Gunn (1994) dengan responden pewakil $(n=8)$ sebagai penilai. Pewakil ini merupakan penduduk asli dan dapat mewakili masyarakat serta mengetahui secara rinci kondisi desa tersebut dan sekitarnya. Penilaian objek wisata dilakukan dengan memenuhi aspek berikut, yaitu aspek keberadaan (letak dari jalan utama), estetika dan keaslian, transportasi dan aksessibilitas, atraksi dan keunikan, fasilitas pendukung, ketersediaan air bersih, dan dukungan masyarakat.

Kemudian dilakukan penilaian berdasarkan ketersediaan objek dan atraksi wisata pada masing-masing zona di lokasi penelitian. Penilaianan tersebut menghasilkan zona wisata berdasarkan ketersediaan objek dan atraksi wisata yang meliputi zona atraktif (S1), zona cukup atraktif (S2), zona kurang atraktif (S3), dan zona tidak atraktif (N).

Zona atraktif merupakan zona wisata dengan tingkat potensi tinggi, yaitu memiliki objek dan atraksi wisata $>5$. Zona cukup atraktif adalah zona wisata dengan potensi wisata sedang, yaitu memiliki objek dan atraksi wisata $3-5$. Zona kurang atraktif adalah zona wisata dengan tingkat potensi rendah yang memiliki objek dan atraksi wisata 1 - 3 . Sedangkan zona tidak atraktif adalah zona tanpa potensi wisata yaitu tidak memiliki objek dan atraksi wisata. 
Penghitungan penilaian terhadap objek dan atraksi wisata :

$$
\sum_{n=1}^{8} \mathrm{Flju}+\sum_{n=1}^{8} \mathrm{Fek}+\sum_{n=1}^{8} \mathrm{Fatk}+\sum_{n=1}^{8} \mathrm{Frp}+\sum_{n=1}^{8} \mathrm{Fka}+\sum_{n=1}^{8} \mathrm{Fta}+\sum_{n=1}^{8} \mathrm{Fdm}
$$

Kesesuaian kawasan agrowisata sangat menentukan objek/atraksi, jalur sirkulasi, aktivitas, dan fasilitas yang akan dikembangkan. Hasil analisis kesesuaian agrowisata digambarkan dalam bentuk peta sebagai dasar untuk perencanaan kawasan agrowisata yang akan dikembangkan.

Penentuan kategori kesesuaian kawasan agrowisata di kawasan bukit Piantus sangat dipengaruhi kondisi biofisik kawasan, penentuannya menggunakan data primer dan sekunder sebagai data atribut pada peta-peta tematik berdasarkan parameter yang diadopsi dari Bakosurtanal (1996) dan Keppres No.32 (1990).

\subsection{Sintesis}

Sintesis merupakan tahap untuk memadukan setiap hasil analisis yang telah didapat sebelumnya. Hasil analisis yang berupa gambar spasial akan disintesiskan dengan cara meng-overlay-kan peta tematik hasil dari analisis data sehingga didapatlah zonasi ruang/block plan tertentu sesuai dengan kebutuhan yang diperlukan untuk pengembangan agrowisata di kawasan wisata bukit Piantus.

\section{Hasil Dan Pembahasan}

\subsection{Konsep Perencanaan Kawasan}

Studi rencana pengembangan lanskap agrowisata di kawasan wisata bukit Piantus bertujuan untuk mengoptimalkan potensi sumberdaya alam pertanian pada tapak bagi pengembangan agrowisata. Konsep dasar pengembangan kawasan ini adalah menciptakan kawasan agrowisata berwawasan pendidikan pertanian, sebagai upaya pengembangan di bidang pertanian berbasis wisata yang dilakukan dengan cara sinergitas antara potensi kawasan (objek wisata) dan kebutuhan wisatawan.

\subsection{Pengembangan Konsep}

Konsep yang ada kemudian dikembangkan menjadi konsep lanskap ruang, sirkulasi, dan aktivitas. Konsep ruang yang akan dikembangkan pada tapak mengikuti kondisi tapak yang ada, dengan kreasi fasilitas penunjang untuk kegiatan wisata budaya, tanpa menghilangkan suasana alami yang ada pada tapak sehingga diharapkan kegiatan wisata dan kehidupan masyarakat berjalan bersama.

\subsubsection{Pengembangan Konsep Ruang}

Konsep ruang dikembangkan berdasarkan potensi pertanian yang terdapat pada kawasan serta memperhatikan kebutuhan ruang wisata bagi pengembangan agrowisata. Ruang yang dikembangkan terbagi atas tiga ruang tujuan wisata, yaitu ruang utama, ruang pendukung serta ruang penyangga agrowisata.

Ruang Utama, merupakan ruang yang dijadikan tempat berlangsungnya aktivitas agrowisata. Ruang ini adalah ruang yang memanfaatkan serta mengembangkan potensi sumberdaya alam berupa komoditas pertanian dan perbukitan pada tapak sebagai objek 
yang dapat dinikmati, serta ruang atraksi agrowisata bagi wisatawan untuk turut serta dalam melakukan aktivitas pertanian.

Ruang Pendukung, merupakan ruang yang berfungsi memberikan pelayanan kepada wisatawan atas kelengkapan, kemudahan dan kenyamanan terhadap aktivitas agrowisata, serta mendukung konsep agrowisata yang diharapkan. Ruang pendukung ini meliputi ruang ruang penerimaan, ruang transisi, dan ruang masyarakat.

Ruang Penyangga, sebagai ruang yang berfungsi untuk menyangga ruang konservasi kawasan terhadap aktivitas wisata serta untuk mempertahankan kelestarian lingkungan sekaligus mempertahankan fungsi kawasan sesungguhnya sebagai daerah resapan air. Di dalam ruang ini tetap dikembangkan aktivitas wisata namun hanya bersifat pasif nonintensif.

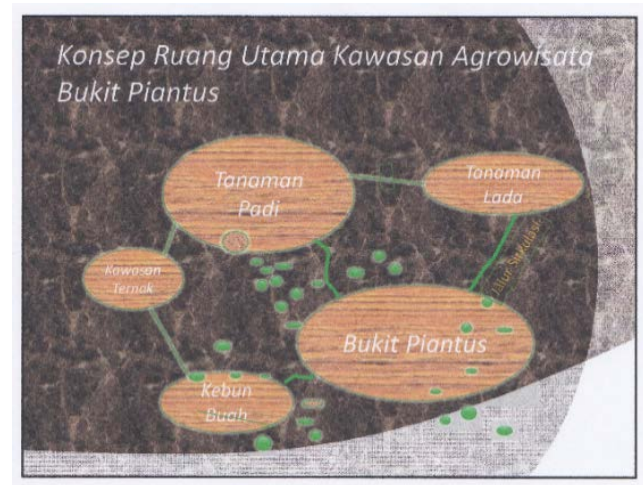

Gambar 1. Konsep Ruang Utama Agrowisata Kawasan Bukit Piantus

\subsubsection{Pengembangan Konsep Aktivitas dan Fasilitas}

Upaya meningkatkan pengetahuan di bidang pertanian melalui cara yang menyenangkan pada kawasan agrowisata dirumuskan ke dalam konsep aktivitas yang direncanakan dan dikembangkan berdasarkan keikutsertaan wisatawan dalam aktivitas pertanian. Jenis aktivitas agrowisata yang akan dikembangkan adalah jenis aktivitas agrowisata aktif dan pasif.

\section{a. Aktivitas Agrowisata Aktif}

Merupakan jenis aktivitas agrowisata yang melibatkan wisatawan secara langsung ke dalam aktivitas pertanian. Wisatawan turut serta secara aktif dalam proses pertanian, mulai dari proses persiapan lahan hingga menghasilkan produk olahan yang dapat dibawa pulang sebagai buah tangan. Pengetahuan pertanian diperoleh melalui pemahaman dan penyampaian nilai pendidikan pertanian secara langsung kepada wisatawan.

b. Aktivitas Agrowisata Pasif

Merupakan aktivitas agrowisata yang lebih rekreatif dan dikembangkan tanpa melibatkan wisatawan secara langsung ke dalam aktivitas pertanian. Nilai pendidikan pertanian diperoleh wisatawan melalui pengamatan dan pemahaman yang dilakukannya sendiri. 


\subsubsection{Pengembangan Konsep Jalur Agrowisata}

Konsep sirkulasi yang dikembangkan dalam kawasan agrowisata bukit Piantus terbagi atas jalur wisatawan dan jalur bagi masyarakat sebagai pendukung aktivitas masyarakat sehari-hari. Konsep jalur agrowisata bagi wisatawan yang dikembangkan berfungsi menghubungkan ruang serta sub-sub ruang agrowisata di dalam kawasan sehingga wisatawan dapat menikmati seluruh objek dan atraksi yang ditawarkan.

Konsep jalur agrowisata bagi wisatawan membagi jalur di dalam kawasan menjadi tiga dengan peruntukan kendaraan berbeda, yaitu jalur primer, sekunder dan tersier. Jalur primer merupakan jalur utama agrowisata yang menghubungkan antar sub ruang agrowisata dengan pintu masuk dan keluar kawasan serta direncanakan menggunakan pola memutar. Hal ini bertujuan untuk memudahkan dalam pengaturan dan kenyamanan wisatawan.

Untuk jalur tersier yang khusus ditujukan bagi pejalan kaki adalah menghubungkan sub-sub ruang di dalam sub ruang agrowisata dengan pola memusat menuju pusat-pusat atraksi agrowisata. Sedangkan jalur sekunder ditujukan bagi kendaraan sepeda, merupakan kombinasi atau memanfaatkan pola kedua jalur tersebut. Adapun gambaran jalus sirkulasi dalam rencana pengembangan kawasan agrowisata bukit Piantus dapat dilihat pada gambar 2 berikut:

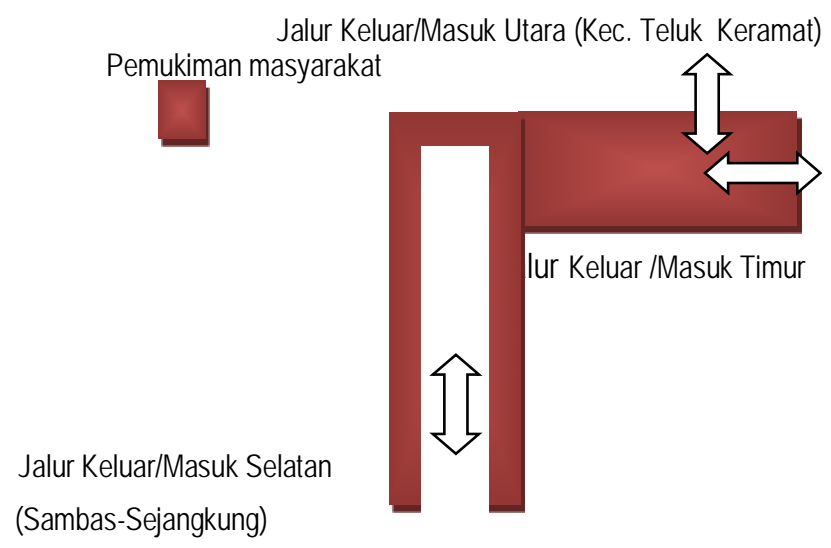

Gambar 2. Jalur Sirkulasi Menuju Lokasi Penelitian

\subsection{Penilaian Objek Agrowisata}

Potensi agowisata di kawasan wisata bukit Piantus kecamatan Sejankung merupakan produk wisata unggulan yang dapat dikembangkan sesuai dengan pola pemanfaatan lahan yang sejalan dengan konsep agrowisata yaitu pemanfaatan lankap pertanian untuk peningkatan kesejahteraan masyarakat lokal. 
Tabel 1. Penilaian Kelayakan Objek dan Atraksi Agrowisata Kawasan Bukit Piantus Parameter

\begin{tabular}{|c|c|c|c|c|c|c|c|c|c|}
\hline $\begin{array}{c}\text { Objekl } \\
\text { Atraksi Wisata }\end{array}$ & 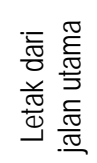 & 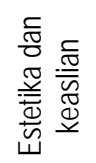 & 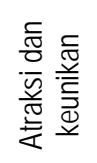 & 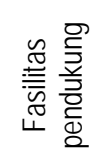 & 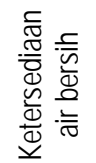 & 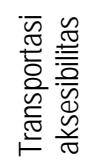 & 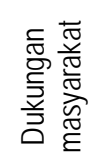 & $\frac{\bar{े}}{\omega}$ & 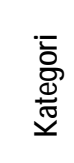 \\
\hline $\begin{array}{l}\text { Kawasan } \\
\text { Pertanian Padi }\end{array}$ & 24 & 16 & 25 & 24 & 24 & 32 & 32 & 177 & S2 \\
\hline $\begin{array}{l}\text { Kawasan } \\
\text { Perkebunan Lada }\end{array}$ & 24 & 18 & 9 & 9 & 24 & 16 & 32 & 132 & S2 \\
\hline $\begin{array}{l}\text { Kawasan } \\
\text { Tanaman Buah }\end{array}$ & 24 & 27 & 32 & 24 & 8 & 10 & 32 & 157 & S2 \\
\hline $\begin{array}{l}\text { Kawasan } \\
\text { Peternakan }\end{array}$ & 24 & 24 & 25 & 17 & 16 & 10 & 32 & 158 & S2 \\
\hline
\end{tabular}

Sumber : Hasil Analisis Data (2016)

Keterangan : Nilai penjumlahan skoring tiap responden $(n=8)$

S1= Sangat Potensial (nilai $193-256$ )

S2 = Cukup Potensial (nilai $129-192$ )

S3 $=$ Kurang Potensial (nilai $65-128$ )

$\mathrm{N}=$ Tidak Potensial (nilai $\leq 64$ )

Potensi agowisata tersebut merupakan potensi utama dimana lebih lanjut perkembangannya akan mempengaruhi potensi lainnya terutama potensi kawasan dan sumber daya manusia yang ada di sekitar wilayah bukit Piantus. Objek dan daya tarik agowisata yang terdapat di sekitar kawasan wisata bukit Piantus meliputi kawasan pertanian padi, kawasan perkebunan lada, kawasan tanaman buah, dan kawasan peternakan masyarakat lokal.

Konsep pengembangan agrowisata di kawasan bukit Piantus mempunyai potensi sebagai salah daerah tujuan wisata yang menjanjikan di Kalimantan Barat. Untuk lebih mengembangkan kegiatan agowisata diperlukan perencanaan kawasan yang sejalan dengan kebutuhan dan keinginan pengunjung dan masyarakat setempat. Untuk menunjang rencana tersebut (bersamaan dengan telah diberlakukannya otonomi daerah), Pemda dapat membuat aturan bersama tentang event development serta menyiapkan kawasan wisata berbasis pertanian. Adanya objek agrwisata di kawasan bukit Piantus memiliki pembeda khas dengan objek wisata di daerah lainnya. Objek-objek tersebut memiliki keunikan dan karakteristik serta atraksi wisata yang menarik. Keunikan yang ada dapat menarik minat wisatawan untuk berkunjung ke kawasan wisata ini. Adapun secara keseluruhan peta rencana pengembangan kawasan wisata bukit Piantus dapat di lihat pada gambar 3 berikut: 


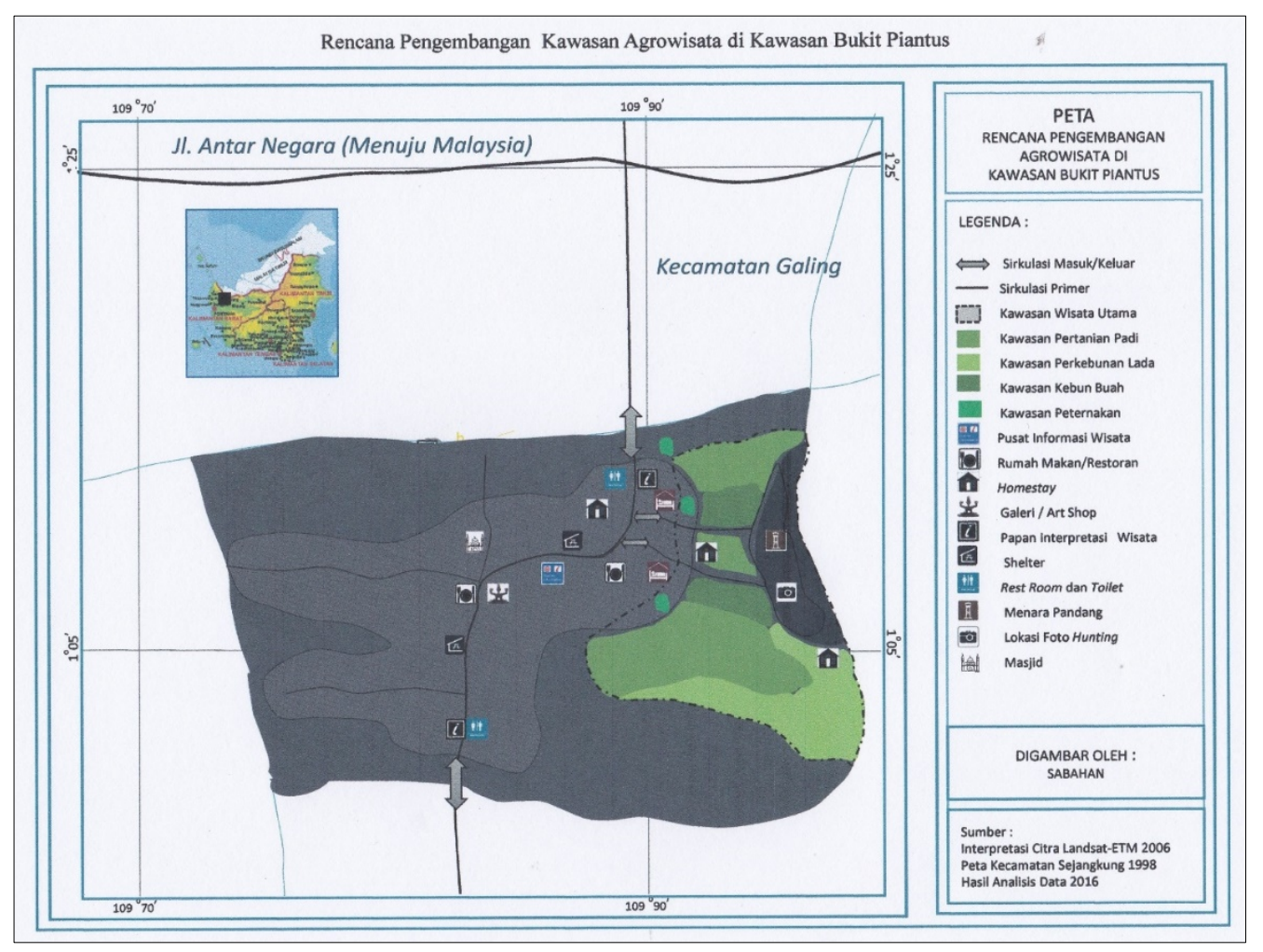

Gambar 3. Peta Rencana Pengembangan Kawasan Wisata Bukit Piantus

\section{Simpulan}

Kawasan bukit Piantus merupakan kawasan wisata yang berada di desa Piantus yang memiliki karakter perbukitan yang didominasi oleh lanskap pertanian. Perencanaan agrowisata dilakukan dengan mengikuti konsep perencanaan lanskap agrowisata yang berbasis pendidikan yang memadukan antara potensi aktivitas budidaya pertanian dengan kondisi alam yang merupakan daerah konservasi untuk meningkatkan kepedulian masyarakat terhadap lingkungan dan dunia pertanian.

Ruang yang direncanakan terbagi menjadi tiga yaitu ruang agrowisata, ruang penunjang agrowisata, dan ruang non agrowisata. Pada masing-masing ruang terdapat fungsi-fungsi tertentu seperti penerimaan, pelayanan, budidaya, pasca panen dan ruang lainnya yang sesuai dengan ruang yang ada.

Aktivitas yang dapat dilakukan di dalam agrowisata ini dapat berupa aktivitas aktif dan pasif. Kegiatan tersebut didukung dengan direncanakannya fasilitas yang memadai yang mencakup fasilitas wisata agro dan fasilitas pelayanan. Selain itu, penambahan utilitas seperti air bersih, listrik, pengolahan sampah dan limbah, dan komunikasi serta promosi akan semakin memperkuat keberadaan agrowisata di kawasan bukit Piantus ke depannya.

\section{Daftar Pustaka}

BAPPEDA Sambas. 2007. Rencana Tata Ruang Wilayah Kabupaten Sambas. PEMDA Sambas. 
BAPPEDA Sambas. 2005. Rencana Pembangunan Jangka Panjang 2005-2020 Kabupaten Sambas. PEMDA Sambas.

[BPS] Badan Pusat Statistik Kabupaten Sambas. 2015. Kabupaten Sambas Dalam Angka. BPS Kabupaten Sambas.

[BPS] Badan Pusat Statistik Kabupaten Sambas. 2015. Kecamatan Sejangkung Dalam Angka. BPS Kabupaten Sambas.

Gunawan, AW, dkk. 2007. Pedoman Penyajian Karya Ilmiah. IPB Press, Bogor.

Gunn, C.A. 1997. Vacationscape: Developing Tourist Area. Taylor \& Francis, USA

Hardjowigeno, S, dkk. 2007. Evaluasi Kesesuaian Lahan Dan Perencanaan Tata Guna Lahan. Gajah Mada University Press, Yogyakarta.

Kantor Desa Piantus. 2016. Potensi Desa Piantus. Kecamatan Sejangkung, Sambas.

Nazir. M, 2006. Metode Penelitian. Ghalia Indonesia, Jakarta.

\section{Ucapan Terima kasih}

Ucapan terima kasih penulis sampaikan kepada Direktorat Pendidikan Tinggi, Politeknik Negeri Sambas, Program Studi Manajemen Bisnis Pariwisata Politeknik Negeri Sambas, dan kawan-kawan dosen di Politeknik Negeri Sambas. Semoga karya ini dapat memberikan manfaat bagi berbagai pihak, khususnya bagi penulis sendiri dan masyarakat di desa Piantus di masa kini maupun masa yang akan datang. 